\section{Molecular Genetic Factors Of Breast Cancer Development (Review)}

\section{Abdulla Nusratillayevich Abdukhakimov, Muqaddas Tukhtabievna Tukhtaboeva}

\author{
Tashkent Regional Branch Of The Republican Specialized \\ Scientific And Practical Medical Center Of Oncology And \\ Radiology, Tashkent, Uzbekistan
}

\author{
G OPEN ACCESS \\ The American Journal Of \\ Medical Sciences And \\ Pharmaceutical \\ Research \\ JULY 2020 \\ Page No.: 112-116 \\ Volume-II Issue-VII \\ PUBLISHED: 31 JULY 2020 \\ www.usajournalshub.com/inde \\ x.php/TAJMSPR \\ Copyright: Original content \\ from this work may be used \\ under the terms of the \\ Creative Commons Attribution \\ 4.0 licence.
}

\title{
Abstract
}

The problem of timely detection of breast cancer is not only in its asymptomatic development, but also in the absence of reliable diagnostic markers that contribute to the early detection of the neoplastic process. The main objectives of oncogenomics are to study the molecular mechanisms of carcinogenesis and develop optimal methods for preventing, diagnosing and monitoring cancer. One approach to solving this problem is to analyze the epigenetic characteristics of the tumor genome.

Keyword: breast cancer, heredity, prevalence, mutations.

\section{Introduction}

It is known that malignant neoplasm are socially significant diseases. Breast cancer (BC), in turn, is one of the most common types of oncopathology, and hereditary forms of breast cancer are often associated with a high risk of developing a primary multiplicity of malignant tumors. Of great importance in the diagnosis and treatment of BC today are biological markers determined directly in the tumor tissue. These markers characterize the individual characteristics of the tumor: a tendency to invasion, metastasis, hormonal sensitivity, etc. [8]. Clarification of the molecular biological and pathogen etic characteristics of $\mathrm{BC}$ makes it possible to get closer to the individualization of systemic therapy and, in some cases, to abandon the obviously ineffective, toxic and expensive 
treatment. The development of an individual approach to the treatment of BC improves the prognosis of the cancer itself and the quality of life in patients [5]. The social significance of $B C$ is so great that scientific research aimed at solving this problem is one of the leading places in modern oncology. It is estimated that over the course of a lifetime, one in 8 women in the United States will develop BC and one in 30 patients with breast cancer will die. BC is the most frequently diagnosed cancer and accounts for $23 \%$ of all primary diagnosed cases of cancer and $14 \%$ of total mortality from cancer $[11,12]$. These neoplasm are characterized by an aggressive course, difficulty in predicting the outcome of the disease and high mortality.

The reasons for the rapid increase in the incidence of $B C$ today include the global urbanization of the environment, the aging of the population, the deterioration of the general environmental situation, man-made disasters, all these factors lead to the steady increase in the number of ontological diseases observed over the past decade [4], including primary multiple malignant tumors (PMMT).

At present, PMMT is understood as the independent emergence and development of two or more neoplasm in one patient. In this case, not only different organs of various systems can be affected, but also paired organs, for example, mammary glands and ovaries. The PMMT phenomenon can occur as a result of various hereditary syndromes, which are the result of specific hereditary mutations that determine the risk of developing cancer in $50 \%$ of offspring, with damage to organs associated with these syndromes. One of the most common familial ontological diseases in women is hereditary $\mathrm{BC}$, the frequency of which is $5-10 \%[2,15]$.

Despite the fact that, in terms of the rate of increase in the incidence, BC takes the leading place among malignant neoplasms, there are still no real tests for early detection of $\mathrm{BC}[3]$.

The problem of timely detection of BC lies not only in its asymptomatic development, but also in the absence of reliable markers that contribute to the early detection of the neoplastic process. According to statistics, $80 \%$ of patients on their own randomly find a tumor, which in half of the cases refers to the advanced stage [9].

The main tasks of oncogenomics are the study of the molecular mechanisms of carcinogenesis and the development of optimal methods for the prevention, diagnosis and monitoring of ontological diseases. One of the approaches to solving this problem is to analyze the epigenetic characteristics of the tumor genome.

The purpose of this review was to study candidate genes of the SFRP family in terms of their potential use as epigenetic markers of BC.

\section{Materials and Methods}

Currently, a number of methods have been developed to detect abnormal methylated loci in the genome of a tumor cell. Analysis of methylation markers is a rather informative tool for molecular genetics diagnostics and monitoring of neoplasm malignancy.

The pronounced heterogeneity at the clinical, histopathological and molecular levels has led to the creation of numerous markers of the disease, which, however, do not always provide a sufficient level of diagnostic efficiency. This explains the need to develop more modern multi-gene marker panels, including methylation marker panels. Modern 
studies indicate the fundamental possibility of using both marker panels and single methylation markers as prognostic and predictive in breast cancer.

\section{Results and Discussion}

The use of an optimized method of unbiased screening of differential methylation of genomes in BC studies has led to the identification of a number of new methods that are being studied both from the point of view of participation in the processes of carcinogenesis, as well as from the point of view of diagnostic applications. The development and implementation of more modern differential methylation screening protocols and the characterization of new markers of abnormal methylation should increase the efficiency of developing BC diagnostic marker systems.

Like most malignant tumors, breast cancer is multi factorial in nature. Most women diagnosed with BC are of sporadic origin, rather than an inherited form of cancer. It is known that the share of hereditary $\mathrm{BC}$ is at least $10-15 \%$ of ovarian cancer cases [2], which is associated with the presence of genetic mutations in one of the two genes for susceptibility to BC BRCA1 or BRCA2 [16]. It should be noted that mutations of these genes at the population level are very rare ( 1 in 400 individuals) and even less often in sporadic forms of these diseases [14]. Rarely, BC is caused by other hereditary syndromes [17].

In the pathogenesis of breast cancer, along with ontogenesis, the tumor suppression genes TSGs (Tumor Suppressor Genes) also play an important role [11]. The inactivation of TSGs, the selective growth of malignant transformed cells, is based on genetic changes, including point mutations, deletions, rearrangements, and epigenetic lesions that affect the temporal and spatial control of gene expression without altering the DNA sequence [3]. The epigenetic mechanisms of reversible changes in the work of the genome do not affect the nucleotide sequence of DNA. The best known epigenetic mechanisms include DNA methylation, post-translational modification of nuclear proteins (histones), and posttranscriptional regulation of the stability of messenger RNAs - mRNAs [1]. Disturbances in the functioning of epigenetic mechanisms controlling the transcriptional activity of the genome play an important role in the process of neoplastic transformation [7].

Methylation is understood as a reversible chemical modification of the DNA structure by the addition of a methyl group to cytosine in the CpG dinucleotide, where the cytosine - guanine pair are sequentially located in the same DNA strand [6]. DNA methylation is one of the main mechanisms for controlling gene expression; changes in the cytosine structure affect the efficiency of binding of transcription factors to regulatory DNA regions. In the process of neoplastic transformation, cytosine hyper methylation is often observed within certain loci, and this phenomenon is called global hypo methylation or a uniform decrease in the degree of methylation of the entire genome. A global decrease in the degree of methylation of genomic DNA accompanies pathological activation of oncogenes and the accumulation of chromosomal aberrations, while local hyper methylation may be accompanied by inhibition of the activity of TSGs genes and genomic instability [6].

One of the earliest and most frequent epigenetic events observed at the initial stages of the development of tumors of various localization is a violation of the epigenetic regulation of gene activity based on their abnormal methylation / dimethylation of one or 
both alleles, which makes it possible to differentiate certain types of tumors [10].

Epigenetic modification of the regulatory regions of genes disrupts their interaction with transcription factors, blocking these regions with the help of proteins (Methyl CpG bindingproteins) that specifically bind to methylated $\mathrm{CpG}$ pairs and, in addition, changes the surrounding chromatin, transforming it into a stably repressed state [18]. This phenomenon is practically not observed in normal tissues, and is called abnormal gene methylation in a tumor.

Unlike mutations, changes in DNA methylation profiles associated with loss of gene expression occur in a specific region of the gene, for example, in the promoter region or the first exon. To date, it has been established that gene methylation is associated with an aggressive tumor and disease progression [13]. Since abnormal methylation is one of the earliest events in the genome of a transformed cell, the nature of methylation of cancerassociated genes can make it possible to diagnose oncopathology at the earliest stages of its onset, i.e. long before clinical signs, which in turn will allow for timely preventive therapy measures [13].

\section{Conclusions}

Thus, the diagnostic potential of abnormal methylation can be used to determine prognostic criteria for the development of BC.

Genes that are methylated during the early phase of tumorigenesis are potential markers for early cancer diagnosis. Genes that undergo methylation during the progression of malignancy are potential predictive markers.

All this determines the need for the development and implementation of automated systems for genetic screening and monitoring of burdened oncological families, identification of hereditary forms of cancer and predisposition to their development.

\section{References}

1. Vanyushin B.F. Epigenetics today and tomorrow // Vavilov Journal of Genetics and Selection. - 2013. - No. 17 (4/2). - S. 805-832. 12

2. Imyanitov E.N., Hanson K.P. Molecular Oncology: Clinical Aspects. - St. Petersburg, 2007 .-- 211 p. 4

3. Kazubskaya TP, Loginov V.I., Khodyrev D.S., Ermilova V.D., Payanidi Yu.G., Chkhikvadze N.V., Selchuk V.Yu., Braga E.A. Methylation of genes RASSF1A, RARß2, SEMA3B in epithelial tumors of the mammary gland, ovaries and polyneoplasia // Tumors of the female reproductive system. - 2012. - No. 1. - S.61-68. 6

4. Kazubskaya T.P., Khodyrev D.S., Pronina I.V., Ermilova V.D., Payanidi Yu.G., Chkhikvadze N.V., Selchuk V.Yu., Braga E.A., Loginov V.I. Methylation of suppressor genes in epithelial tumors of the mammary gland and ovaries, including primary multiple // Russian Biotherapeutic Journal. - 2012. - No. 1. - Volume 11. - P.69-74.-3

5. Laptiev SA, Korzhenevskaya MA, Imyanitov EN Molecular genetic "portrait" of breast cancer. Scientific notes of St. acad. I.P. Pavlova. 2017; 24 (2): 12-22. DOI: 10.24884 / 1607-4181-2017-24-2-12-22.

6. Savitsky S.E. Modern concepts of the mechanisms of carcinogenesis in breast cancer 
(literature review) // Journal of the GrSMU 2008 № 4, pp. 10-14

7. Samsonov R.B., Radzhabova Z.A., Cheburkin Yu.V., Kluge V.A., Tkachenko E.V., Malek A.V. Epigenetic mechanisms of gene expression regulation in the development of squamous cell carcinoma of the head and neck: therapeutic perspectives // Head and neck tumors. - 2016. - Issue 4. - Volume 6. - P.35-44. fourteen

8. Semiglazov VF, Semiglazov VV Screening of breast cancer // Practice. oncol. - 2010. - No. 11 (2). - S. 60-65.

9. Tamkovich S.N., Voitsitsky V.E., Laktionov P.P. Modern methods for diagnosing breast cancer // Biomedical chemistry. - 2014. - Volume 60. - Issue 2. - P.141-160. 7

10. Esteller M. Epigenetics in cancer. N Engl J Med. 2008; 358(11): 1148-1159. 13

11. Ferlay J.S.I., Ervik M., Dikshit R., Eser S., Mathers C., Rebelo M., Parkin D.M., Forman D., Bray F. GLOBOCAN 2012 v1.0,cancer incidence and mortality worldwide: IARC Cancer Base. 2013. N11. International Agency for Research on Cancer, Lyon.http://globocan.iarc.fr. Accessed on 17 Aug 2014-2

12. Jemal A., Bray F., Center M.M., Ferlay J., Ward E., Forman D. Global cancer statistics. CA Cancer J Clin. 2011; 61: 69- 90. -1

13. Li Z., Guo X., Wu Y., Li S., Yan J., Peng L., Xiao Z., Wang S., Deng Z., Dai L., Yi W., Xia K., Tang L., Wang J. Methylation profiling of 48 candidate genes in tumor and matched normal tissues from breast cancer patients. Breast Cancer Res Treat. 2015; 149(3): 767779. 24

14. Narod S.A., Foulkes W.D. BRCA1 and BRCA2: 1994 and beyond. Nat Rev Cancer 2004; (9): 665-676 9

15. Nicoletto M.O., Donach M., De Nicolo A., Artioli G., Banna G. BRCA-1 and BRCA-2 mutations as prognostic factors in clinical practice and genetic counselling. Cancer Treat Rev 2011. 27: 295-330. 5

16. Petrucelli N, Daly MB, Pal T. BRCA1- and BRCA2-Associated Hereditary Breast and Ovarian Cancer. 1998 Sep 4 [updated 2016 Dec 15]. In: Adam MP, Ardinger HH,Pagon RA, Wallace SE, Bean LJH, Stephens K, Amemiya A, editors. GeneReviews ${ }^{\circledR}$ [Internet]. Seattle (WA): University of Washington, Seattle; 1993-2018 8

17. Suh D.H., Kim M., Lee K.H., Eom K.Y., Kjeldsen M.K., Mirza M.R., Kim J.W. Major clinical research advances in gynecologic cancer in 2017. J Gynecol Oncol. 2018; 29(2): 31.10

Tang W, Wang C, Fu F, Chen Q. RhoBTB2 gene in breast cancer is silenced bypromoter methylation. Int J Mol 